\title{
Local empirical model of ionospheric plasma density derived from Digisonde measurements at Irkutsk
}

\author{
K. G. Ratovsky and A. V. Oinats \\ Institute of Solar-Terrestrial Physics, 664033, Lermontov st., 126a, P.O. Box 291, Irkutsk, Russia
}

(Received June 7, 2010; Revised March 7, 2011; Accepted March 7, 2011; Online published June 14, 2011)

\begin{abstract}
Ionogram data from routine ionospheric observations in Irkutsk, Russia using a DPS-4 Digisonde sounder were hand-scaled for the 6-year period from December 2002 to December 2008 to derive a local empirical model of the electron density distribution in the bottomside ionosphere that provides a comprehensive description of the diurnal, seasonal, and solar activity variations of the major ionospheric characteristics. The paper describes the technique for building the local empirical model and the results of comparing its diurnal, seasonal, and solar activity specifications with the standard IRI-2007 climatological model for the same period of time, and retrospective observational data from the Millstone Hill incoherent scatter radar (1976-2002) and a collocated Digisonde (1989-1990, 1998-2004). Reasoning for the observed differences between the three datasets is then provided in terms of background physical phenomena. Primary focus of the paper is the behavior of three $F_{2}$ layer characteristics: the $F_{2}$ peak density $\left(N_{\mathrm{m}} F_{2}\right)$, the peak height $\left(h_{\mathrm{m}} F_{2}\right)$ and the bottomside thickness $\left(B_{0}\right)$.
\end{abstract}

Key words: Local model, Digisonde, IRI model, diurnal-seasonal-solar activity behavior.

\section{Introduction}

The DPS-4 Digisonde (Reinisch et al., 1997) was installed at Irkutsk, Russia $(52.3 \mathrm{~N}, 104.3 \mathrm{E})$ in November, 2002. All Digisonde ionogram data have been manually scaled using an interactive ionogram scaling software, SAO Explorer (Reinisch et al., 2004; Khmyrov et al., 2008). The electron density profiles (EDP) were inverted from all suitable ionogram traces using the NHPC method (Reinisch and Huang, 1983). In addition to the EDP itself, NHPC provides two standard IRI parameters for the EDP representation, the bottomside thickness $B_{0}$ and the shape parameter $B_{1}$ using the Reinisch and Huang (1998) technique. In order to validate the quality of the observational data, the ionospheric $F$ region parameters measured with the DPS-4 were compared to available data from a co-located chirpionosonde (Brynko et al., 1988) and the Irkutsk incoherent scatter radar (Shpynev, 2004); this comparison revealed no systematic discrepancies between the data from the different instruments for quiet geomagnetic conditions (Ratovsky et al., 2005).

Six years of the hand-scaled ionospheric characteristics from December 2002 to December 2008 were used to build a local empirical model of ionospheric electron density (LEMI) for Irkutsk. The Irkutsk LEMI model complements monthly-median climatological ionospheric specifications provided by global models like the IRI-2007 (Bilitza and Reinisch, 2008) by accounting for the regional specifics of the ionospheric plasma distribution that elude detailed reproduction in a global model. Study of the comprehen-

Copyright (C) The Society of Geomagnetism and Earth, Planetary and Space Sciences (SGEPSS); The Seismological Society of Japan; The Volcanological Society of Japan; The Geodetic Society of Japan; The Japanese Society for Planetary Sciences; TERRAPUB.

doi:10.5047/eps.2011.03.002 sive patterns of the diurnal, seasonal, and solar activity variations of ionospheric characteristics provided by LEMI makes our model a useful tool for understanding the physical mechanisms of these variations.

The following sections compare the LEMI diurnal, seasonal, and solar activity behavior with the IRI-2007 (Bilitza and Reinisch, 2008) prediction and with long-term observational data from the Millstone Hill $(42.6 \mathrm{~N}, 288.5 \mathrm{E})$ incoherent scatter radar (1976-2002), the co-located ionosonde (1989-1990, 1998-2004) (Lei et al., 2004, 2005), and other instruments. Comparison of LEMI with data from a different mid-latitude location allowed us to identify the longitudinal differences in the local ionospheric specifications. We then discuss observed differences in the context of background physical phenomena. For the purpose of such comparison, we selected three $F_{2}$ layer parameters: the $F_{2}$ peak density $\left(N_{\mathrm{m}} F_{2}\right)$, the peak height $\left(h_{\mathrm{m}} F_{2}\right)$, and the bottomside thickness $\left(B_{0}\right)$ and used the latest IRI-2007 model version (Bilitza and Reinisch, 2008) with the following options: URSI maps for $N_{\mathrm{m}} F_{2}$, CCIR maps for $h_{\mathrm{m}} F_{2}$, and the Gulyaeva option for $B_{0}$.

\section{LEMI Construction Technique}

The source data for the empirical model representation are the ionospheric characteristics obtained by the Irkutsk Digisonde operating at a 15-minute cadence. Each measured characteristic $P$ is considered as a function of local time (LT), day of year (D) and year (Y), i.e., $P$ (LT, D, Y). In order to represent the regular part of the observed $P$ (LT, $\mathrm{D}, \mathrm{Y}$ ) behavior that we expect to be associated with climatological specifics of the diurnal, seasonal, and long-term solar activity variations, we used the 27-day sliding window median $P_{\text {med }}$ (LT, D, Y) for each combination of LT, $\mathrm{D}$, and $\mathrm{Y}$ in the sets $\{P(\mathrm{LT}, \mathrm{D}-13, \mathrm{Y}), \cdots, P(\mathrm{LT}, \mathrm{D}+13$, 
Y\}. As shown in numerous data analysis applications, use of the median filtering instead of a classic averaging preserves strong gradients in the source data while suppressing the short-term variability with periods below the filter length (27 days in our case). No data (including high magnetic activity conditions) were removed from the median calculations.

As a unit of annual variations we selected the month (M) equal to $T / 12$, where $T=365.25$ days is the solar year $\left(\mathrm{Y}_{\mathrm{S}}\right)$. The solar year $\mathrm{Y}_{\mathrm{S}}$ starts from the winter solstice of leap year (December 21). The month continuously varies from 0 to 12 , the month $=0$ corresponds to the beginning of $Y_{S}$. Since the same days of different years do not correspond exactly to equal month values, we transformed $P_{\text {med }}$ (LT, D, Y) to $P_{\text {med }}\left(\mathrm{LT}, \mathrm{M}, \mathrm{Y}_{\mathrm{S}}\right.$ ) at equal month steps using simple linear interpolation. Hereinafter, we use traditional month names, implying that the zero month is December, the 1st month is January, the 2nd is February, and so on. The beginnings of December and June correspond to the winter and summer solstices and the beginnings of March and September refer to the spring and autumn equinoxes.

Calculated $P_{\text {med }}(\mathrm{LT}, \mathrm{D}, \mathrm{Y})$ are then converted into a $P_{\text {med }}$ $\left(\mathrm{LT}, \mathrm{M}, \mathrm{Y}_{\mathrm{S}}\right.$ ) representation suitable for describing the annual variations, where $\mathrm{Y}_{\mathrm{S}}$ is the solar year, and the month $\mathrm{M}$ is equal to $T / 12$, where $T=365.25$ days of $\mathrm{Y}_{\mathrm{S}}$. The solar year $Y_{S}$ starts from the winter solstice of a leap year (December 21). The month continuously varies from 0 to 12 , with the 0th month corresponding to the beginning of $Y_{S}$. Since the same days of different years do not correspond exactly to equal month values, we had to transform $P_{\text {med }}$ (LT, $\mathrm{D}, \mathrm{Y})$ to $P_{\text {med }}\left(\mathrm{LT}, \mathrm{M}, \mathrm{Y}_{\mathrm{S}}\right)$ at equal one-month steps using a simple linear interpolation. In the rest of our manuscript, we use conventional month names, implying that the 0th month is December, the 1st month is January, etc. In this presentation, December begins on the winter solstice, June begins on the summer solstice, and March and September begin on the spring and autumn equinoxes.

The 27-day running medians were used as an input for LEMI. The main assumption is that the $P_{\text {med }}$ (LT, M, $\mathrm{Y}_{\mathrm{S}}$ ) can be approximated by a linear function of a suitable solar activity index. As a solar activity proxy we selected the $10.7 \mathrm{~cm}$ solar radio flux $\left(F_{10.7}\right)$ whose daily values are available from WDC-A in Boulder, Colorado (ftp://ftp.ngdc.noaa.gov/STP/SOLAR_DATA) in solar flux units s.f.u. (1 s.f.u. $=10^{-22} \mathrm{~W} \mathrm{~m}^{-2} \mathrm{~Hz}^{-1}$ ). Dependence of $P_{\text {med }}$ on $\mathrm{Y}_{\mathrm{s}}$ is therefore replaced by a linear function on $F_{10.7}$, so that $P_{\text {med }}$ (LT, M, $F_{10.7}$ ) is used for further derivations, with the source values of $F_{10.7}$ linearly interpolated to appropriately obtain the solar radio flux values for any given $\mathrm{M}$ and $\mathrm{Y}_{\mathrm{S}}$. Under assumption of its linear dependence on $F_{10.7}$, each model characteristic can be presented in the slope-intercept form:

$$
\begin{aligned}
P_{\text {med }}\left(\mathrm{LT}, \mathrm{M}, F_{10.7}\right)= & P_{0}(\mathrm{LT}, \mathrm{M})+P_{\mathrm{D}}(\mathrm{LT}, \mathrm{M}) \\
& \cdot\left(F_{10.7}-F_{10.70}\right) / F_{10.7100},
\end{aligned}
$$

where $P_{0}$ is the intercept value of the characteristic $P_{\text {med }}$ for the low solar activity of $F_{10.70}=70$ s.f.u. and $P_{\mathrm{D}}$ is the slope value, $d P_{\text {med }} / d F_{10.7}$, describing how sensitive the characteristic $P$ is to changes in the solar activity. For convenience of the presentation the $P_{\mathrm{D}}$ values are calculated

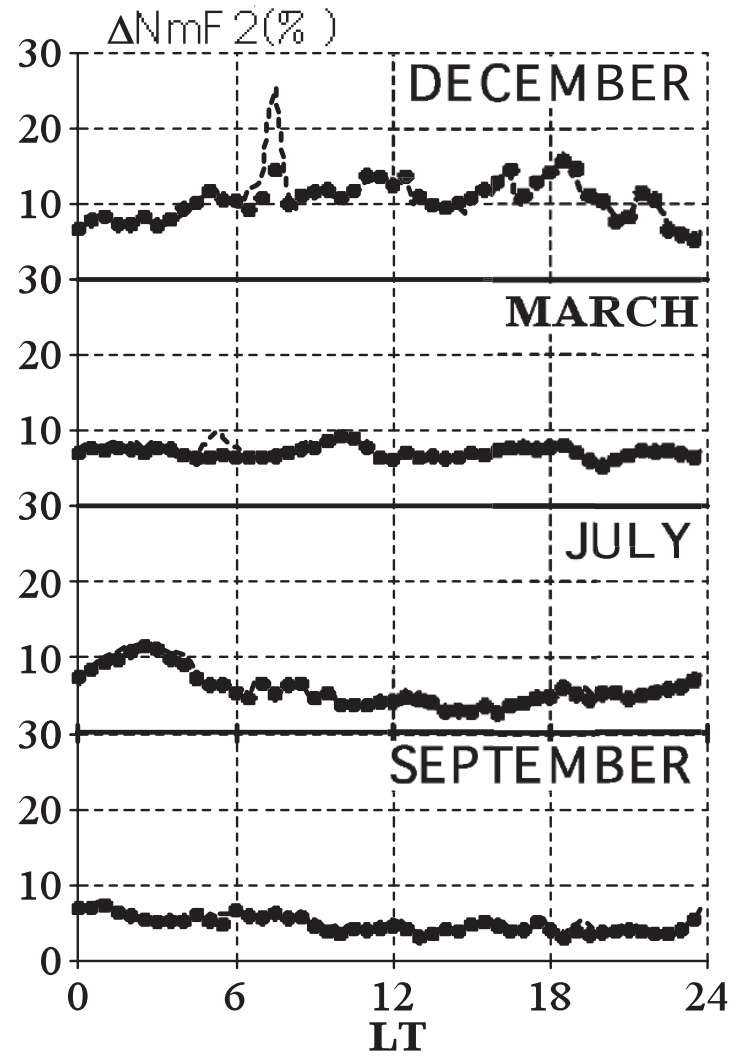

Fig. 1. Relative root mean square deviations $\left(\Delta N_{\mathrm{m}} F_{2}\right)$ between 15-minute time step medians of $N_{\mathrm{m}} F_{2}$ and the values calculated with the LEMI under local steps equal to 0.5 hour (dashed line) and 1 hour (circles).

per increment of $F_{10.7100}=100$ s.f.u., and in the remainder of this manuscript they are expressed in the units of (characteristic unit / 100 s.f.u.).

The model parameters $P_{0}(\mathrm{LT}, \mathrm{M})$ and $P_{\mathrm{D}}(\mathrm{LT}, \mathrm{M})$ can be obtained by the linear regression of $P_{\text {med }}\left(\mathrm{LT}, \mathrm{M}, F_{10.7}\right)$ on $F_{10.7}$. The quality of the linear fit turns out to be dependent on the amount of averaging applied to the daily $F_{10.7}$ values. We tested different sliding window averaging periods for $F_{10.7}$ (from 27 days to 1 year) in order to minimize the linear regression RMS error. For most of the available $P_{\text {med }}$ data, the 1 year period gave the best fit, with exception of December daytime, for which the 27 day period was optimal. Generally, median data are not well correlated with the solar activity intra year variations (from 27 days to 1 year) with the exception of December daytime. This fact is in agreement with our previous studies (Ratovsky et al., 2009) where the difference between the observed $f_{\mathrm{o}} F_{2}$ medians and IRI prediction was found to be poorly correlated with the $F_{10.7}$ intra year variations. Finally, we selected the 1-year running mean of daily $F_{10.7}$ as a solar activity proxy input for LEMI.

Once $P_{0}(\mathrm{LT}, \mathrm{M})$ and $P_{\mathrm{D}}(\mathrm{LT}, \mathrm{M})$ sets are available for discrete values of LT (15 minute increments) and M (0 to 11 ), the next step is to interpolate them over LT and M so that $P_{0}$ and $P_{\mathrm{D}}$ can be obtained for any given local time and month. We used a cardinal B-spline approximation (Schoenberg, 1969) to represent $P_{0}$ and $P_{\mathrm{D}}$ sets continuously, calculating the spline coefficients with a fixed month step $\Delta \mathrm{M}=1$ and various local time steps $\Delta \mathrm{LT}$ ranging 
Table 1. Construction of the LEMI model.

1. Calculation of the 27-day running medians of the ionospheric characteristics $P_{\text {med }}$ (LT, D, Y).

2. Transformation of $P_{\text {med }}(\mathrm{LT}, \mathrm{D}, \mathrm{Y})$ to $P_{\text {med }}\left(\mathrm{LT}, \mathrm{M}, \mathrm{Y}_{\mathrm{S}}\right.$ ) at equal month steps using linear interpolation.

3. Calculation of the two sets of model parameters, (a) low solar activity set $P_{0}(\mathrm{LT}, \mathrm{M})$ and (b) slope of the linear dependence on

$F_{10.7}, P_{\mathrm{D}}(\mathrm{LT}, \mathrm{M})$, using the linear regression of $P_{\text {med }}\left(\mathrm{LT}, \mathrm{M}, F_{10.7}\right)$ on 1-year running mean of $F_{10.7}$.

4. Calculation of the B-spline coefficients for $P_{0}$ and $P_{\mathrm{D}}$ sets with local time step $\Delta \mathrm{LT}=0.5$ hour and month step $\Delta \mathrm{M}=1$.

from 0.25 to 1 hour to select the optimal time resolution of the approximation. Figure 1 shows the relative root mean square differences $\Delta N_{\mathrm{m}} F_{2}$ between 15-minute time step medians of $N_{\mathrm{m}} F_{2}$ and the LEMI values with $\Delta$ LT resolution of 0.5 and 1.0 hour. The $\Delta N_{\mathrm{m}} F_{2}$ values are obtained by averaging the differences over all the years of observations for each month. Observed differences are due to the $F_{10.7}$ linear regression error and inaccuracy of the B-spline approximation. We found that $\Delta N_{\mathrm{m}} F_{2}$ values observed for different local time resolutions $\Delta \mathrm{LT}$ are very similar except for the morning time interval around 7-8 LT in December. Such similarity is typical for all winter months, and for this reason we used 0.5-hour local time step for all B-spline approximations. Table 1 summaries the important steps required for the construction of the LEMI model.

In order to compare LEMI results with the IRI empirical model we calculated $P_{0}$ and $P_{\mathrm{D}}$ coefficients using IRI predicted values as the source data and following steps $2-4$ of the technique. The comparisons are presented in following sections

\section{Results and Discussion}

\section{1 $\mathrm{N}_{\mathrm{m}} \mathrm{F}_{2}$ morphology}

The LEMI diurnal-seasonal behavior of $N_{\mathrm{m}} F_{2}$ for low solar activity $\left(F_{10.7}=70\right.$ s.f.u. $)$ as a function of local time LT and month $\mathrm{M}$ is shown in Fig. 2(a). The high and low values are depicted by the solid and dashed contours, respectively. The daytime seasonal variations show two local maxima: in March $\left(\sim 4 \cdot 10^{5} \mathrm{~cm}^{-3}\right)$ and October $\left(\sim 5 \cdot 10^{5}\right.$ $\left.\mathrm{cm}^{-3}\right)$ and two local minima: in January $\left(\sim 3.1 \cdot 10^{5} \mathrm{~cm}^{-3}\right)$ and July $\left(\sim 2.7 \cdot 10^{5} \mathrm{~cm}^{-3}\right)$. The nighttime $N_{\mathrm{m}} F_{2}$ is largest in June and smallest in January, with intermediate values between these months. Maximum $N_{\mathrm{m}} F_{2}$ during the late evening hours (20-22 LT) occurs in May, one month earlier than during the nighttime.

The Irkutsk daytime seasonal pattern of $N_{\mathrm{m}} F_{2}$ differs from the Millstone Hill pattern (Lei et al., 2005) where daytime $N_{\mathrm{m}} F_{2}$ is largest in the winter and smallest in the summer, with intermediate values at equinoxes. This difference has been reproduced by the Coupled ThermosphereIonosphere-Plasmasphere model (Zou et al., 2000) and explained by the dependence of the winter down welling zone latitude on the geomagnetic longitude (Rishbeth et al., 2000a) that makes a "far-from-the-pole" station (Irkutsk) different from a "near-the-pole" station (Millstone Hill) during the same season.

We can distinguish three types of $N_{\mathrm{m}} F_{2}$ diurnal behavior under low solar activity. The winter-like (OctoberFebruary) pattern is characterized by the main maximum near noon, the local post midnight maximum (2-2:30 LT), and two local minima in the evening (18:30-21 LT) and
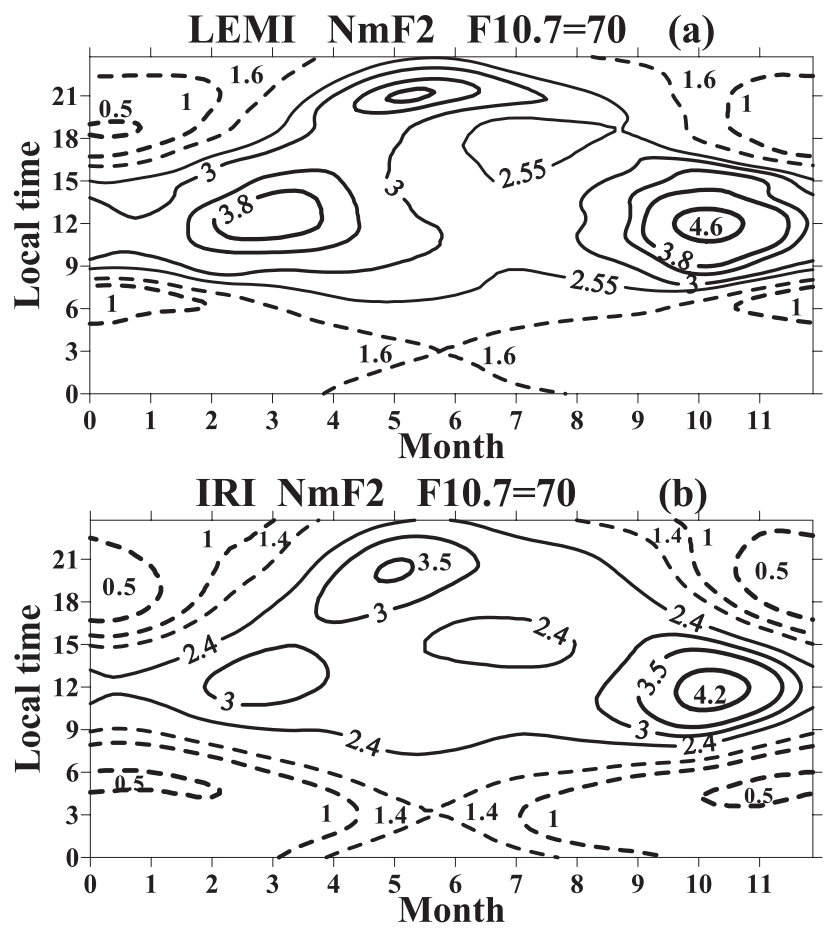

Fig. 2. Diurnal-seasonal variations of $N_{\mathrm{m}} F_{2}$ in $\left[10^{5} \mathrm{~cm}^{-3}\right]$ under low solar activity for LEMI (a) and IRI (b). The high and low values are depicted by the solid and dashed contours, respectively.

in the morning (6-7 LT). Typical summer (May-July) behavior is characterized by the main evening maximum ( $\sim 21 \mathrm{LT})$, the main morning minimum $(\sim 3 \mathrm{LT})$, the local prenoon maximum $(\sim 11 \mathrm{LT})$, and the local afternoon minimum (15 LT in May and 17 LT in June, July). Typical equinox (March, September) pattern is characterized by only one maximum near noon and one minimum in the morning ( 5 LT).

The IRI prediction (Fig. 2(b)) of the $N_{\mathrm{m}} F_{2}$ diurnalseasonal behavior under low solar activity reproduces the LEMI pattern reasonably well, though IRI systematically underestimates both the maxima and minima of $N_{\mathrm{m}} F_{2}$ obtained with LEMI.

The study of the $P_{\mathrm{D}}$ slope as a function of LT and M provides insight into how the ionospheric diurnal-seasonal pattern changes with increasing solar activity. Figure 3(a) shows the LEMI diurnal-seasonal behavior of the $N_{\mathrm{m}} F_{2 \mathrm{D}}$ in $\left[10^{5} \mathrm{~cm}^{-3} / 100\right.$ s.f.u.] units. The daytime $N_{\mathrm{m}} F_{2}(11-$ $13 \mathrm{LT})$ is most sensitive to solar activity near the winter solstice $\left(N_{\mathrm{m}} F_{2 \mathrm{D}} \sim 1410^{5} \mathrm{~cm}^{-3} / 100\right.$ s.f.u. $)$ and least sensitive near the summer solstice $\left(N_{\mathrm{m}} F_{2 \mathrm{D}} \sim 3-3.610^{5} \mathrm{~cm}^{-3} / 100\right.$ s.f.u.), with intermediate values at equinoxes (9-10.5 $10^{5}$ $\mathrm{cm}^{-3} / 100$ s.f.u. in March and 7-8.5 $10^{5} \mathrm{~cm}^{-3} / 100$ s.f.u. in 


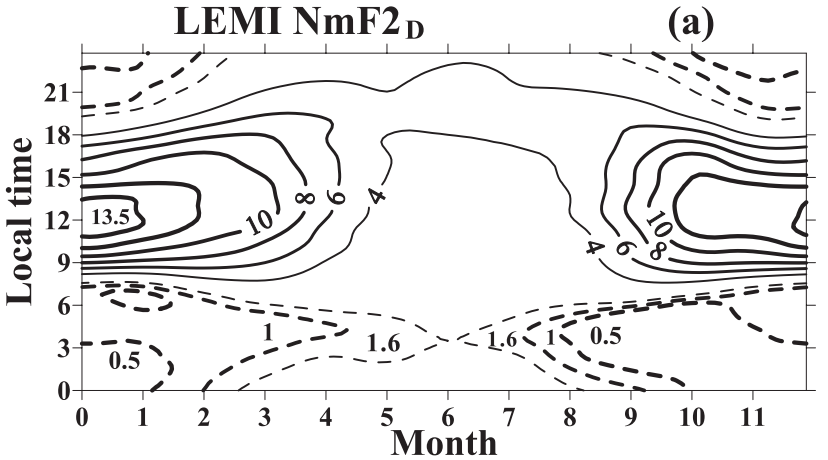

IRI $\mathrm{NmF}_{\mathrm{D}}$

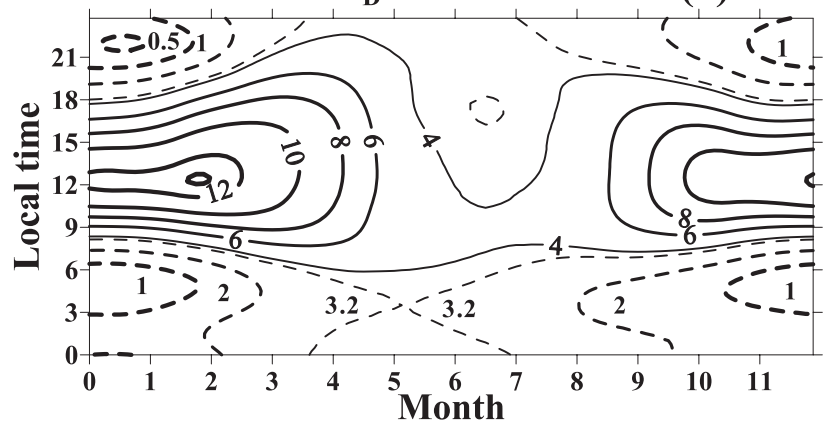

Fig. 3. Diurnal-seasonal variations of the slope of the linear dependence on $F_{10.7}, N_{\mathrm{m}} F_{2 \mathrm{D}}$ in $\left[10^{5} \mathrm{~cm}^{-3} / 100\right.$ s.f.u.] for LEMI (a) and IRI (b). The high and low values are depicted by the solid and dashed contours, respectively.

September). Thus, with increasing solar activity the daytime $N_{\mathrm{m}} F_{2}$ peak moves from March and October towards the winter solstice. This peculiar behavior agrees with the ionospheric maps developed by Torr and Torr (1973) that, for high solar activity, reproduce larger values of winter critical frequency $f_{\mathrm{o}} F_{2}$ than the summer and equinox $f_{\mathrm{o}} F_{2}$ for all considered midlatitude stations. The Irkutsk LEMI daytime seasonal pattern of the $N_{\mathrm{m}} F_{2 \mathrm{D}}$ agrees with both Millstone Hill (Lei et al., 2005) and the IRI patterns (Fig. 3(b)).

According to LEMI (Fig. 3(a)), the summer (May-July) diurnal behavior of $N_{\mathrm{m}} F_{2}$ is characterized by the highest sensitivity to solar activity during the evening hours $\left(N_{\mathrm{m}} F_{2 \mathrm{D}} \sim 19-20 \mathrm{LT}, 4-510^{5} \mathrm{~cm}^{-3} / 100\right.$ s.f.u. $)$, the lowest sensitivity during the morning $\left(N_{\mathrm{m}} F_{2 \mathrm{D}} \sim 3: 30 \mathrm{LT}, \sim 1.5\right.$ $10^{5} \mathrm{~cm}^{-3} / 100$ s.f.u.), and monotonic increase from morning to evening. Such LEMI behavior means that the prenoon $N_{\mathrm{m}} F_{2}$ maximum that we observed in the summer diurnal pattern for low $F_{10.7}$ disappears with increasing solar activity. As for the IRI prediction (Fig. 3(b)), the diurnal maximum of the summer $N_{\mathrm{m}} F_{2 \mathrm{D}}$ is seen at prenoon and noon hours, rather than in the evening, which makes the evening and prenoon maxima of $N_{\mathrm{m}} F_{2}$ comparable to each other with increasing solar activity. This disagreement between the IRI-predicted and the observed summer diurnal behavior of $f_{\mathrm{o}} F_{2}$ was discussed previously by Ratovsky et al. (2009). The Irkutsk summer diurnal behavior of the $N_{\mathrm{m}} F_{2 \mathrm{D}}$ slope differs from the Millstone Hill behavior (Lei et al., $2005)$, where the summer $N_{\mathrm{m}} F_{2 \mathrm{D}}$ varies only weakly during the day (2-3 $10^{5} \mathrm{~cm}^{-3} / 100$ s.f.u.).

Figure 3(a) also demonstrates that there is an area of extremely weak dependence of $N_{\mathrm{m}} F_{2}$ on solar activity
$\left(N_{\mathrm{m}} F_{2 \mathrm{D}}<0.510^{5} \mathrm{~cm}^{-3} / 100\right.$ s.f.u. $)$ in the postmidnight hours. This means that the enhancement of postmidnight $N_{\mathrm{m}} F_{2}$ gets weaker with increasing solar activity, which agrees with the studies of Mikhailov et al. (2000). The authors explained this phenomenon by suggesting that the nighttime recombination rate increases faster than the nighttime influx from the plasmasphere with increasing solar activity.

Ratovsky et al. (2009) observed that the solar activity dependence of the diurnal $f_{\mathrm{o}} F_{2}$ minimum at Irkutsk is much weaker than the IRI prediction. This disagreement manifests itself in the difference between the postmidnight $N_{\mathrm{m}} F_{2 \mathrm{D}}$ obtained with LEMI and IRI. According to IRI, the average postmidnight (0-3 LT) $N_{\mathrm{m}} F_{2 \mathrm{D}}$ varies from 1.1 to $3.510^{5} \mathrm{~cm}^{-3} / 100$ s.f.u. (from December to June), whereas the LEMI values are 0.4 and $2.510^{5} \mathrm{~cm}^{-3} / 100$ s.f.u. for December and June, respectively. The Millstone Hill (Lei et $a l ., 2005)$ average postmidnight summer $N_{\mathrm{m}} F_{2 \mathrm{D}}$ is close to the LEMI value, whereas the winter $N_{\mathrm{m}} F_{2 \mathrm{D}}$ is close to the IRI prediction for Irkutsk. Possibly, the balance between the recombination rate and the plasmasphere influx, and hence the postmidnight $N_{\mathrm{m}} F_{2 \mathrm{D}}$ depends on the geographic location. In support of this explanation, modeling by Zou et al. (2000) showed that the December midnight ratio $N_{\mathrm{m}} F_{2}$ $\left(F_{10.7}=180\right) / N_{\mathrm{m}} F_{2}\left(F_{10.7}=100\right)$ is the smallest at "farfrom-the-pole" longitudes.

\section{$3.2 h_{\mathrm{m}} F_{2}$ morphology}

Figure 4(a) shows the LEMI diurnal-seasonal behavior of the $F_{2}$ peak height $h_{\mathrm{m}} F_{2}$ under low solar activity $\left(F_{10.7}=70\right.$ s.f.u. $)$. The high (nighttime) and low (daytime) values are depicted by the solid and dashed contours, respectively. The average daytime (10-14 LT) seasonal variations show an annual pattern with the December minimum $(209 \mathrm{~km})$ and the April-May maximum $(228 \mathrm{~km})$. The average nighttime (22-02 LT) seasonal variations also show an annual pattern with the June-July minimum $(282 \mathrm{~km})$ and the November maximum $(294 \mathrm{~km})$. Both daytime and nighttime seasonal patterns of LEMI are somewhat different from the IRI model (Fig. 4(b)) that predicts a semiannual pattern both for average daytime (10-14 LT) and nighttime (22-02 LT) $h_{\mathrm{m}} F_{2}$. The daytime $h_{\mathrm{m}} F_{2}$ has local maxima in March $(243 \mathrm{~km})$ and September $(240 \mathrm{~km})$, and local minima in July $(210 \mathrm{~km})$ and January $(218 \mathrm{~km})$. The nighttime $h_{\mathrm{m}} F_{2}$ has local maxima in March $(324 \mathrm{~km})$ and October $(313 \mathrm{~km})$, and local minima in July $(292 \mathrm{~km})$ and December $(302 \mathrm{~km})$.

Figure 5(a) shows diurnal-seasonal dependence of $h_{\mathrm{m}} F_{2}$ on solar activity by plotting $h_{\mathrm{m}} F_{2 \mathrm{D}}$ values in units of [km/100 s.f.u.]. The peak height of the ionosphere is most sensitive to the solar activity $\left(h_{\mathrm{m}} F_{2 \mathrm{D}}>70\right)$ in the postmidnight hours. Another area of strong dependence $\left(h_{\mathrm{m}} F_{2 \mathrm{D}}>\right.$ $60)$ is seen in the afternoon hours in October and from March to August. The area of weak dependence of $h_{\mathrm{m}} F_{2}$ on solar activity $\left(h_{\mathrm{m}} F_{2 \mathrm{D}}<50\right)$ is seen in the prenoon hours for all months except October and in the late evening hours for all months except June and July.

The pattern of the LEMI diurnal-seasonal behavior of $h_{\mathrm{m}} F_{2 \mathrm{D}}$ is different from both the IRI prediction (Fig. 5(b)) and the Millstone Hill data (Lei et al., 2005). IRI predicts that the $h_{\mathrm{m}} F_{2 \mathrm{D}}$ is approximately proportional to the 
Table 2. Daytime and nighttime annual mean of $h_{\mathrm{m}} F_{2}\left(F_{10.7}=140\right)$ in $[\mathrm{km}]$ and $h_{\mathrm{m}} F_{2 \mathrm{D}}$ in $[\mathrm{km} / 100$ s.f.u.] for different stations. The station coordinates are shown in parentheses. Dip is the magnetic field dip angle of the station.

\begin{tabular}{|c|c|c|c|c|c|}
\hline \multirow[t]{2}{*}{ Station } & \multirow[t]{2}{*}{$\operatorname{Dip}\left({ }^{\circ}\right)$} & \multicolumn{2}{|c|}{ Daytime } & \multicolumn{2}{|c|}{ Nighttime } \\
\hline & & $h_{\mathrm{m}} F_{2}\left(F_{10.7}=140\right)$ & $h_{\mathrm{m}} F_{2 \mathrm{D}}$ & $h_{\mathrm{m}} F_{2}\left(F_{10.7}=140\right)$ & $h_{\mathrm{m}} F_{2 \mathrm{D}}$ \\
\hline Sodankyla (67N, 27E) & 76 & 270 & 35 & 374 & 46 \\
\hline Moscow $(56 N, 37 E)$ & 71 & 268 & 46 & 374 & 50 \\
\hline Irkutsk (52N, 104E) & 72 & 263 & 61 & 340 & 73 \\
\hline IRI prediction for Irkutsk & & 272 & 66 & 331 & 36 \\
\hline Slough $(52 \mathrm{~N}, 1 \mathrm{~W})$ & 67 & 258 & 48 & 378 & 43 \\
\hline Millstone Hill (43N, 288E) & 70 & 265 & 46 & 333 & 33 \\
\hline Wallops Is (38N, 75W) & 70 & 268 & 44 & 348 & 37 \\
\hline Wakkanai (38N, 142E) & 51 & 272 & 57 & 366 & 56 \\
\hline Norfolk Is (29S, 168E) & 56 & 282 & 45 & 340 & 38 \\
\hline Mundaring (32S, 116E) & 66 & 275 & 38 & 338 & 33 \\
\hline Kerguelen (49S, 70E) & 67 & 297 & 40 & 340 & 48 \\
\hline Port Stanley (52S, 58W) & 47 & 261 & 61 & 387 & 55 \\
\hline
\end{tabular}

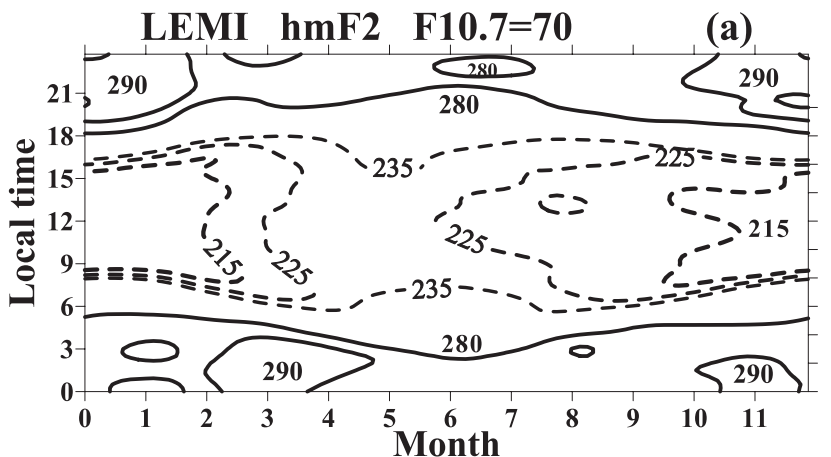

IRI hmF2 F10.7=70

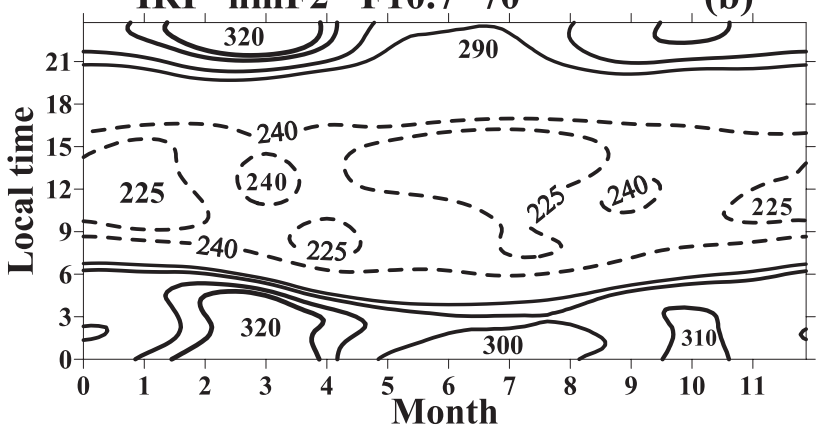

Fig. 4. Diurnal-seasonal variations of $h_{\mathrm{m}} F_{2}$ in [km] under low solar activity for LEMI (a) and IRI (b). The high and low values are depicted by the solid and dashed contours, respectively.

solar zenith angle, so that highest sensitivity to increasing solar activity level $\left(h_{\mathrm{m}} F_{2 \mathrm{D}}>60\right)$ is seen in the daytime hours ( $\sim 6-15 \mathrm{LT})$ for the summer and equinox months. At Millstone Hill (Lei et al., 2005) $h_{\mathrm{m}} F_{2 \mathrm{D}}$ remains below 56 $\mathrm{km} / 100$ s.f.u., with higher values during daytime than at night, a diurnal peak at around 1300-1400 LT in all seasons, and a weaker dependence in winter than in other seasons.

We compared the LEMI daytime (10-14 LT) and nighttime (22-02 LT) annual mean of $h_{\mathrm{m}} F_{2 \mathrm{D}}$ with values observed at midlatitude stations (Rishbeth et al., 2000b). Table 1 demonstrates the daytime and nighttime annual mean of $h_{\mathrm{m}} F_{2 \mathrm{D}}$ and $h_{\mathrm{m}} F_{2}\left(F_{10.7}=140\right.$ s.f.u. $)$. Except for Irkutsk and Millstone Hill, the observational data are taken from the paper of Rishbeth et al. (2000b). The Irkutsk

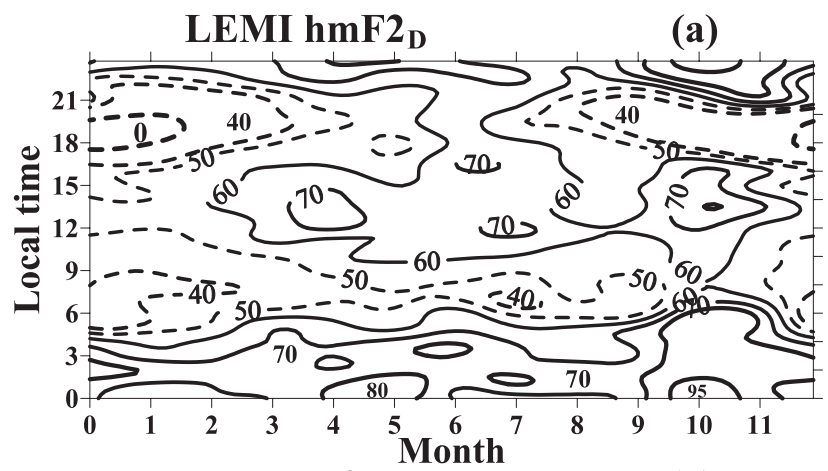

IRI hmF2

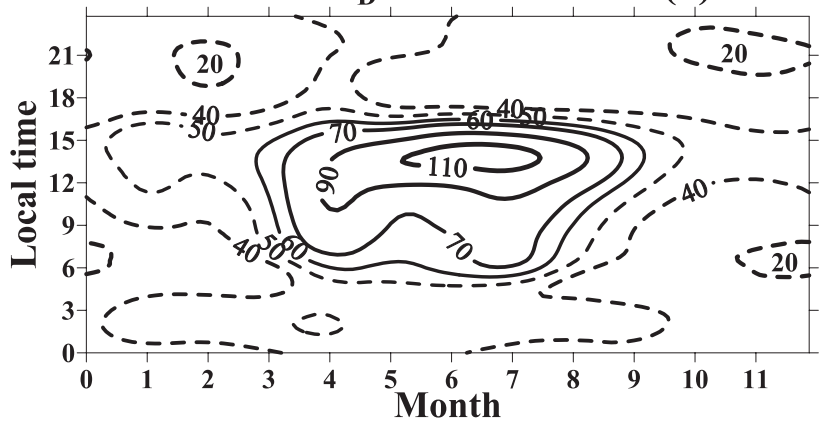

Fig. 5. Diurnal-seasonal variations of the slope of the linear dependence on $F_{10.7}, h_{\mathrm{m}} F_{2 \mathrm{D}}$ in $[\mathrm{km} / 100$ s.f.u.] for LEMI (a) and IRI (b). The high and low values are depicted by the solid and dashed contours, respectively.

$h_{\mathrm{m}} F_{2}\left(F_{10.7}=140\right)$ was calculated using expression (1) and LEMI values of $h_{\mathrm{m}} F_{20}$ and $h_{\mathrm{m}} F_{2 \mathrm{D}}$. Using the same technique, we calculated Millstone Hill $h_{\mathrm{m}} F_{2}\left(F_{10.7}=140\right)$ using the data of Lei et al. (2005). One can see from Table 2 that $h_{\mathrm{m}} F_{2}$ is most sensitive to solar activity for the "farfrom-the-pole" stations (Port Stanley, Wakkanai, Irkutsk) and this sensitivity is not correlated to the magnetic field dip angle.

\section{3 $B_{0}$ morphology}

The LEMI diurnal-seasonal behavior of the bottomside thickness $B_{0}$ under low solar activity $\left(F_{10.7}=70\right.$ s.f.u. $)$ is shown in Fig. 6(a). The high and low values are depicted by the solid and dashed contours, respectively. 
Table 3. Mean nighttime (22-02 LT) and mean daytime (10-14 LT) values of $B_{0 \mathrm{D}}$ in $[\mathrm{km} / 100$ s.f.u.] averaged over the three seasons.

\begin{tabular}{|l|c|c|c|c|c|c|}
\hline \multirow{2}{*}{ Season } & \multicolumn{3}{|c|}{ Nighttime } & \multicolumn{3}{c|}{ Daytime } \\
\cline { 2 - 7 } & Irkutsk LEMI & IRI prediction for Irkutsk & Millstone Hill & Irkutsk LEMI & IRI prediction for Irkutsk & Millstone Hill \\
\hline Winter & 18 & 11 & 15 & 15 & 14 & 15 \\
\hline Equinox & 19 & 12 & 15 & 19 & 22 & 15 \\
\hline Summer & 28 & 12 & 30 & 20 & 48 & 20 \\
\hline
\end{tabular}

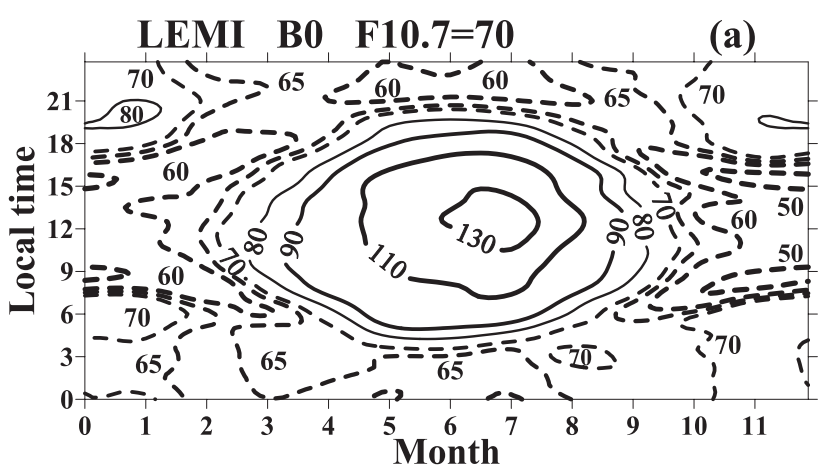

IRI BO F10.7 =70

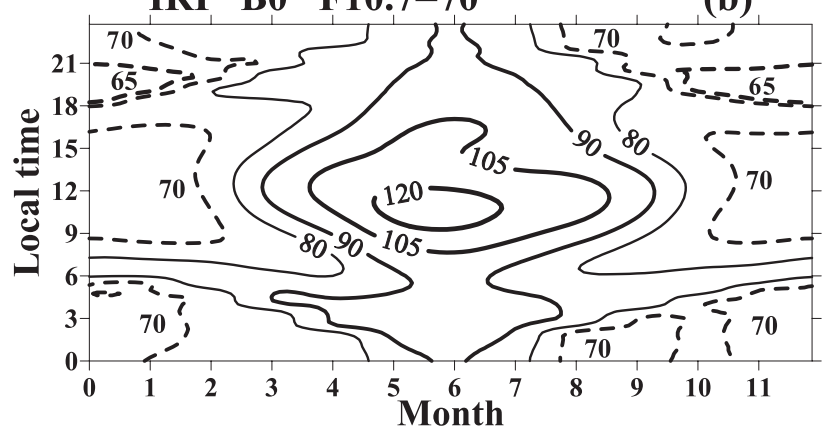

Fig. 6. Diurnal-seasonal variations of $B_{0}$ in $[\mathrm{km}]$ under low solar activity for LEMI (a) and IRI (b). The high and low values are depicted by the solid and dashed contours, respectively.

Diurnal behavior of $B_{0}$ during winter and equinox (from September to March) is characterized by so called morning and evening collapses (Lei et al., 2004) when $B_{0}$ is minimal. The local times of the collapses (8:45-6:00 and 15:15-18:00 LT) are close to the times of sunrise and sunset at zero altitude. The $B_{0}$ at the minima increases from $47-48 \mathrm{~km}$ at the winter solstice to $57-63 \mathrm{~km}$ at the spring and autumn equinoxes. In November-January the midnight $B_{0}(70-75 \mathrm{~km})$ exceeds the noon one $(56-59 \mathrm{~km})$, in March and September the noon $B_{0}(84 \mathrm{~km})$ exceeds the midnight one $(66-69 \mathrm{~km})$, and in October and February the noon and midnight $B_{0}$ values $(64-68 \mathrm{~km})$ are comparable. So, in winter and equinox months the diurnal-seasonal pattern of $B_{0}$ is close to being symmetric about noon as well as the winter solstice. The summer-like (April-August) diurnal behavior is characterized by the only one maximum near noon (12:30-12:45 LT) and one minimum in the late evening hours (21:15-21:45 LT, $\left.B_{0}=\sim 60 \mathrm{~km}\right)$. Maximum diurnal $B_{0}$ values rise from $99 \mathrm{~km}$ in April to $137 \mathrm{~km}$ in July and after that decrease to $116 \mathrm{~km}$ in August. The average daytime (10-14 LT) seasonal variations of $B_{0}$ show an annual pattern with the December minimum $(56 \mathrm{~km})$ and the July maximum $(133 \mathrm{~km})$. The average nighttime $(22-$

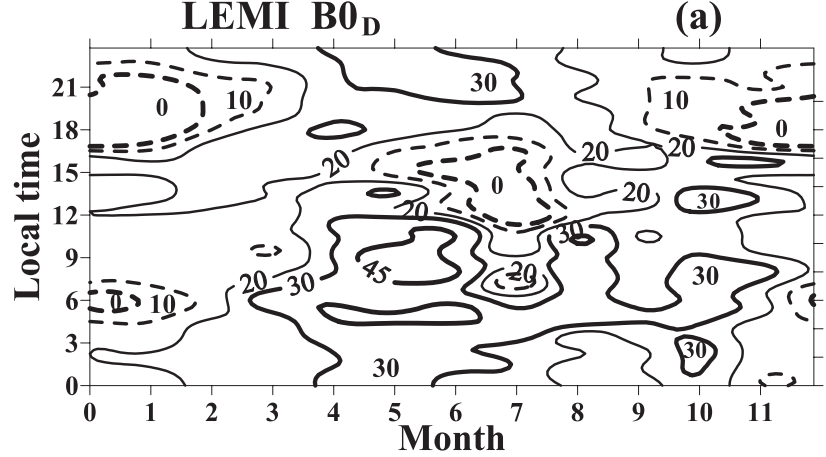

IRI $\mathrm{BO}_{\mathrm{D}}$

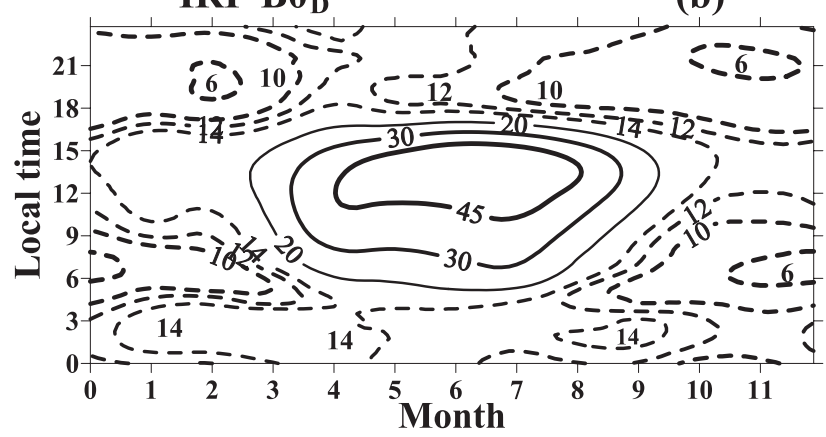

Fig. 7. Diurnal-seasonal variations of the slope of the linear dependence on $F_{10.7}, B_{0 \mathrm{D}}$ in $[\mathrm{km} / 100$ s.f.u.] for LEMI (a) and IRI (b). The high and low values are depicted by the solid and dashed contours, respectively.

02 LT) seasonal variations also show an annual pattern with the May minimum $(63 \mathrm{~km})$ and the November maximum $(75 \mathrm{~km})$.

In general, diurnal-seasonal pattern of $B_{0}$ is close to that at Millstone Hill (Lei et al., 2004). There are differences in the nighttime behavior. At Millstone Hill the winter noon and midnight values are close together, and the nighttime $B_{0}$ does not show an evident seasonal effect.

The LEMI diurnal-seasonal behavior of $B_{0}$ is somewhat different from the IRI prediction (Fig. 6(b)). IRI predicts a well-pronounced morning maximum (dominant for the winter months), which is not observed in the LEMI pattern. The IRI's evening collapse occurs later in the evening hours (18-21 LT) in comparison to LEMI. Both models give comparable daytime seasonal patterns of $B_{0}$, though IRI overestimates the winter $B_{0}$ and underestimates the summer $B_{0}$. Compared to LEMI, the IRI predicts an opposite nighttime seasonal behavior with the December minimum $(68 \mathrm{~km})$ and the June maximum $(92 \mathrm{~km})$.

The LEMI diurnal-seasonal behavior of the $B_{0}$ sensitivity to increasing solar activity level, $B_{0 \mathrm{D}}$, is shown in Fig. 7(a). No clear diurnal-seasonal pattern of $B_{0 \mathrm{D}}$ can be seen. In contrast to LEMI, IRI gives a clear pattern of $B_{0 \mathrm{D}}$ 
(Fig. 7(b)). Similar to $h_{\mathrm{mD}}$ IRI preducts greater dependence of $B_{0}$ on solar activity $\left(B_{0 \mathrm{D}}>60 \mathrm{~km} / 100\right.$ s.f.u. $)$ in the daytime hours ( $\sim 6-15 \mathrm{LT})$ from March to September.

Millstone Hill data (Lei et al., 2004) suggest that increase of solar activity level from low $\left(F_{10.7}=90\right.$ s.f.u. $)$ to high $\left(F_{10.7}=180\right.$ s.f.u. $)$ results in increase of $B_{0}$ by about $30 \%$ during the night and by about $20 \%$ during the day, except for the morning collapse periods in equinox and winter when $B_{0}$ increases by less than $10 \%$. In order to compare these observations with LEMI, we had to regroup and average our data to match Lei et al. (2004) technique of binning data into three seasons, namely summer (May-August), winter (November-February), and equinox (March, April, September and October). We averaged the LEMI and IRI mean nighttime (22-02 LT) and mean daytime (10-14 LT) values of $B_{0 \mathrm{D}}$ over the three seasons. Using available Millstone Hill observations of $B_{0}$ under low $\left(F_{107}=90\right.$ s.f.u. $)$ and high $\left(F_{107}=180\right.$ s.f.u. $)$ solar activity (Lei et al., 2004), we obtained estimates of $B_{0 \mathrm{D}}$. Table 3 shows the final results. For the nighttime, the IRI $B_{0 \mathrm{D}}$ does not show any seasonal variations; whereas both the Irkutsk LEMI and Millstone Hill summer $B_{0 \mathrm{D}}$ noticeably exceeds the winter one and the equinox $B_{0 \mathrm{D}}$ is close to the winter one. In all presented cases, the summer daytime $B_{0 \mathrm{D}}$ exceeds the winter one, but the IRI summer daytime $B_{0 \mathrm{D}}$ noticeably overestimates both the Irkutsk LEMI and Millstone Hill ones.

\section{Conclusion}

Data from routine ionospheric observations at Irkutsk, Russia using a DPS-4 Digisonde sounder were used to derive a local empirical model of the electron density that provides a comprehensive description of the diurnal, seasonal, and solar activity variations of the major ionospheric characteristics. We have compared the local model patterns with the IRI-2007 prediction (Bilitza and Reinisch, 2008) and the retrospective data from long-term mid-latitude measurements by the Millstone Hill incoherent scatter radar and the collocated Digisonde (Lei et al., 2004, 2005).

The comparison revealed both similarities and differences between Irkutsk and Millstone Hill diurnal, seasonal and solar activity variations. The observed disagreements can in part be explained by the different location of the instruments at "far-from-the-pole" and "near-the-pole" longitudes. The observed strong dependence of the nighttime $h_{\mathrm{m}} F_{2}$ on the level of solar activity is found to be in agreement with the observations at "far-from-the-pole" sites reported by Rishbeth et al. (2000b). Many of the local Irkutsk model features, such as the diurnal-seasonal pattern of $N_{\mathrm{m}} F_{2}$ under low solar activity and the slope of the daytime $N_{\mathrm{m}} F_{2}$ dependence on $F_{10.7}$, are reasonably well reproduced by the IRI prediction, although there are differences.

In winter and equinox months the diurnal-seasonal pattern of $B_{0}$ under low solar activity is found to be nearly symmetric about noon as well as the winter solstice. This feature will be useful for empirical modeling. The local model does not give a clear diurnal-seasonal pattern of the slope of $B_{0}$ dependence on $F_{10.7}$, but season averages of the daytime and nighttime $B_{0}$ do agree with available Millstone Hill observations.

Acknowledgments. The authors would like to thank Dr. Ivan Galkin of UMass Lowell Center for Atmospheric Research for his helpful comments and suggestions.

\section{References}

Bilitza, D. and B. Reinisch, International Reference Ionosphere 2007: Improvements and new parameters, J. Adv. Space Res., 42, 599-609, 2008.

Brynko, I. G., I. A. Galkin, V. P. Grozov, N. I. Dvinskikh, S. M. Matyuoshonok, and V. E. Nosov, An automatically controlled data gathering and processing system using an FMCW ionosonde, Adv. Space Res., 8, 121-124, 1988.

Lei, J., L. Liu, W. Wan, S.-R. Zhang, and J. M. Holt, A statistical study of ionospheric profile parameters derived from Millstone Hill incoherent scatter radar measurements, Geophys. Res. Lett., 31, L14804, doi:10.1029/2004GL020578, 2004.

Lei, J., L. Liu, W. Wan, and S.-R. Zhang, Variations of electron density based on long-term incoherent scatter radar and ionosonde measurements over Millstone Hill, Radio Sci., 40, RS2008, doi:10.1029/2004RS003106, 2005.

Khmyrov, G. M., I. A. Galkin, A. V. Kozlov, B. W. Reinisch, J. McElroy, and C. Dozois, Exploring digisonde ionogram data with SAO-X and DIDBase, Radio Sounding and Plasma Physics, AIP Conf. Proc., 974, 175-185, 2008.

Mikhailov, A. V., M. Förster, and T. Y. Leschinskaya, On the mechanism of the post-midnight winter NmF2 enhancements: dependence on solar activity, Ann. Geophys., 18, 1422-1434, 2000.

Ratovsky, K. G., V. P. Grozov, A. G. Kim, A. V. Medvedev, A. P. Potekhin, and B. G. Shpynev, Comparison of the ionospheric F Region parameters measured with the DPS-4 Digisonde, LFM ionosonde, and incoherent backscatter radar in Irkutsk during the magnetic storm of October 2931, 2003, Geomagn. Aeron., 45, 129-133, 2005.

Ratovsky, K. G., A. V. Oinats, and A. V. Medvedev, Diurnal and seasonal variations of F2 layer characteristics over Irkutsk during the decrease in solar activity in 2003-2006: Observations and IRI-2001 model predictions, Adv. Space Res., 43, 1806-1811, 2009.

Reinisch, B. W. and X. Huang, Automatic calculation of electron density profiles from digital ionograms, 3, Processing of bottomside ionograms, Radio Sci., 18, 477-492, 1983.

Reinisch, B. W. and X. Huang, Finding better B0 and B1 parameters for the IRI F2-profile function, Adv. Space Res., 22, 741-747, 1998.

Reinisch, B. W., D. M. Haines, K. Bibl, I. Galkin, X. Huang, D. F. Kitrosser, G. S. Sales, and J. L. Scali, Ionospheric sounding support of OTH radar, Radio Sci., 32, 1681-1694, 1997.

Reinisch, B. W., I. A. Galkin, G. Khmyrov, A. Kozlov, and D. F. Kitrosser, Automated collection and dissemination of ionospheric data from the digisonde network, Adv. Radio Sci., 2, 241-247, 2004.

Rishbeth, H., I. C. F. Müller-Wodarg, L. Zou, T. J. Fuller-Rowell, G. H. Millward, R. J. Moffett, D. W. Idenden, and A. D. Aylward, Annual and semiannual variations in the ionospheric F2-layer: II. Physical discussion, Ann. Geophys., 18, 945-956, 2000a.

Rishbeth, H., K. J. F. Sedgemore-Schulthess, and T. Ulich, Semiannual and annual variations in the height of the ionospheric F2-peak, Ann. Geophys., 18, 285-299, 2000b.

Schoenberg, I. J., Cardinal interpolation and spline functions, J. Approximation Theory, 2, 167-206, 1969.

Shpynev, B. G., Incoherent scatter Faraday rotation measurements on a radar with single linear polarization, Radio Sci., 39, RS3001, doi:10.1029/2001RS002523, 2004.

Torr, M. R. and D. G. Torr, The seasonal behaviour of the F2-layer of the ionosphere, J. Atmos. Terr. Phys., 35, 2237-2251, 1973.

Zou, L., H. Rishbeth, I. C. F. Müller-Wodarg, A. D. Aylward, G. H. Millward, T. J. Fuller-Rowell, D. W. Idenden, and R. J. Moffett, Annual and semiannual variations in the ionospheric F2-layer: I. Modelling, Ann. Geophys., 18, 927-944, 2000.

K. G. Ratovsky (e-mail: ratovsky@iszf.irk.ru) and A. V. Oinats 